\title{
C-H Activation, a New Strategy for Synthesis of 3-Substituted Phthalides
}

\author{
Qianqian Sun, Runqing Zhu, Shuyu Hu, and Lizhen Fang* \\ School of Pharmacy, Xinxiang Medical University, Xinxiang, Henan 453003, China \\ Email: 2002flz@163.com (L. F.)
}

\begin{abstract}
Phthalides are an important class of compounds owing to their role as the key structural motifs in bioactive natural products and pharmaceutical synthesis. $\mathrm{C}-\mathrm{H}$ activation has become a promising strategy for preparation of phthalides due to its advantages of high efficiency and atomic economy compared with the traditional methods. In this paper, we summarized recent advances on synthesis of 3-substituted phthalides via $\mathrm{C}-\mathrm{H}$ activation according to different transition metal catalytic systems.
\end{abstract}

Keywords synthesis, 3-substituted phthalides, $\mathrm{C}-\mathrm{H}$ activation, catalysis

\section{Introduction}

Phthalides, known as o-hydroxymethyl benzoolactone, is composed of a $y$-lactone ring and a benzene ring. 3-Substituted phthalides have been widely present in natural products and clinic drugs, ${ }^{[1-4]}$ which are important pharmacoactive groups and intermediates in pharmaceutical synthesis. Additionally, they have important and significant biological activity (Figure 1). The traditional method (Scheme 1) for synthesizing 3-substituted phthalides ${ }^{[5]}$ usually have some drawbacks of many steps and low atom utilization. As a potent tool developed in recent years, $\mathrm{C}-\mathrm{H}$ activation is presently widely used in the preparation of many drugs possessing several advantages of simplicity, high efficiency and environmentally friendly. Herein, we reviewed nearly 30 methods for synthesis of 3-substituted phthalides via $\mathrm{C}-\mathrm{H}$ activation in recent years to provide an overview in this research field.

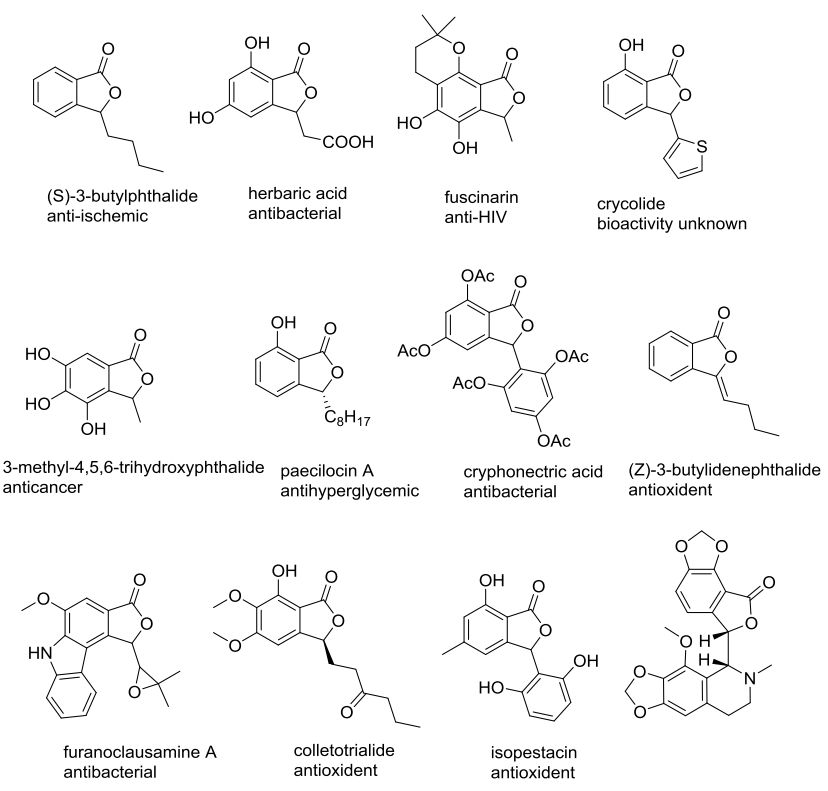

Figure 1 Representative examples of 3-substituted phthalides and biologically.
Scheme 1 The traditional methods for synthesizing 3-substituted phthalides

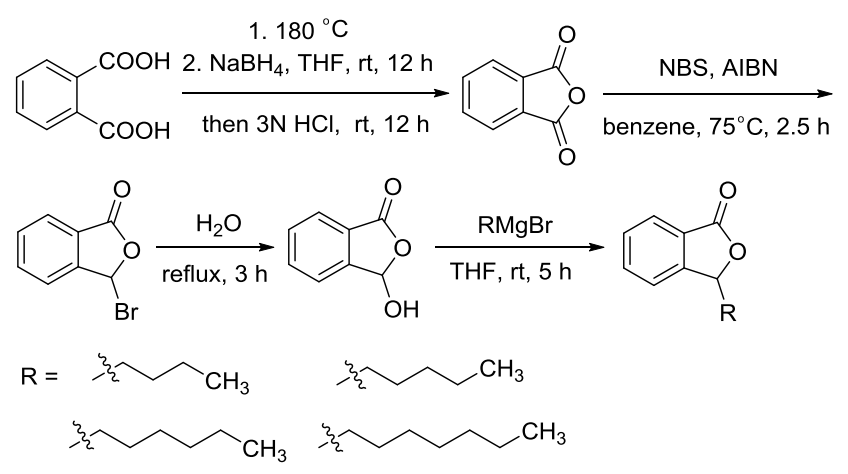

\section{Synthesis of 3-Substituted Phthalides Using Palladium Catalysts}

As early as 1998, Miura et al. ${ }^{[6]}$ firstly reported that $\operatorname{Pd}(\mathrm{OAc})_{2}$ catalyzed the reaction of benzoic acid with olefins (Scheme 2). The reaction with $10 \mathrm{~mol} \%$ of $\mathrm{Pd}(\mathrm{OAc})_{2}$ as a catalyst, 1 equivalent of $\mathrm{Cu}(\mathrm{OAc})_{2} \cdot \mathrm{H}_{2} \mathrm{O}$ as an oxidant. When benzoic acid has a substituent at the ortho position, a five-membered heterocycle is formed through the migration and insertion of olefin to obtain 3-substituted phthalides due to the steric effects. Otherwise, it is easy to form a six-member heterocyclic. Notably, they disclosed a case of $n$-butyl acrylate as the reactant, and the alkylation product 3-butylphthalide acetate is obtained by Michael addition reaction.

The $\mathrm{C}-\mathrm{C}$ and $\mathrm{C}-\mathrm{O}$ coupling reactions of benzoic acid were reported with a $\mathrm{Pd}(\mathrm{OAc})_{2}$ catalyst by Yu et al..$^{[7]}$ (Scheme 3). Dibromomethane with benzoic acid generated five-membered ring lactone. The addition of inorganic base plays a key role in promoting reaction such as $\mathrm{K}_{2} \mathrm{HPO}_{4}, \mathrm{KHCO}_{3}$ and $\mathrm{Na}_{2} \mathrm{CO}_{3}$. It has good adaptability to both electron-rich and electron-deficient substrates.

In the following research, Martin et al. ${ }^{[8]}$ reported an improved reaction to synthesize 3 -substituted phthalides. $\mathrm{Pd}(\mathrm{OAc})_{2}$ was used as a catalyst, $\mathrm{Ag}_{2} \mathrm{CO}_{3}$ (3 equiv.) was used as an oxidant, $\mathrm{K}_{2} \mathrm{HPO}_{4}$ (2.5 equiv.) was added as a base, and $\mathrm{N}$-acetylleucine also played an important role in promoting the reaction as ligands (Scheme 4). Compared with previous works, the system achieved higher yields and substrate compatibility. 
Scheme 2 Pd-catalyzed alkenylation and alkylation of benzoic acid with olefin and proposed mechanism
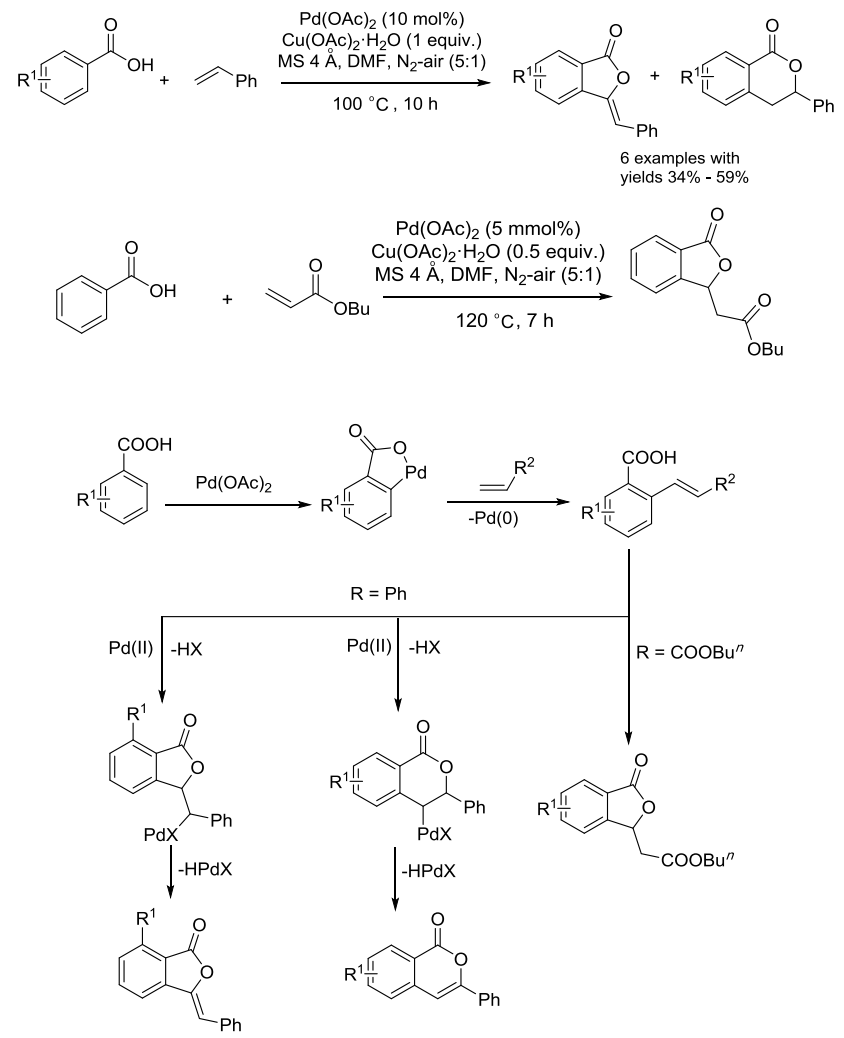

Scheme $3 \quad \mathrm{Pd}(\mathrm{OAc})_{2}$ catalytic benzoic acid ortho-C-H activation

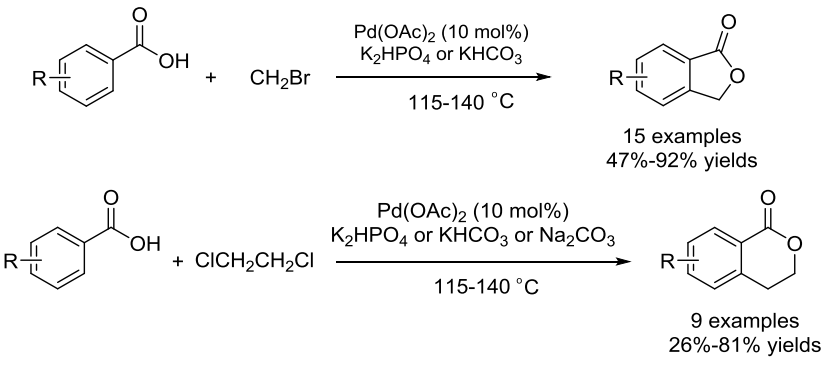

Scheme 4 Pd-catalyzed benzoic acid for the synthesis of 3-substituted phthalides and proposed mechanism
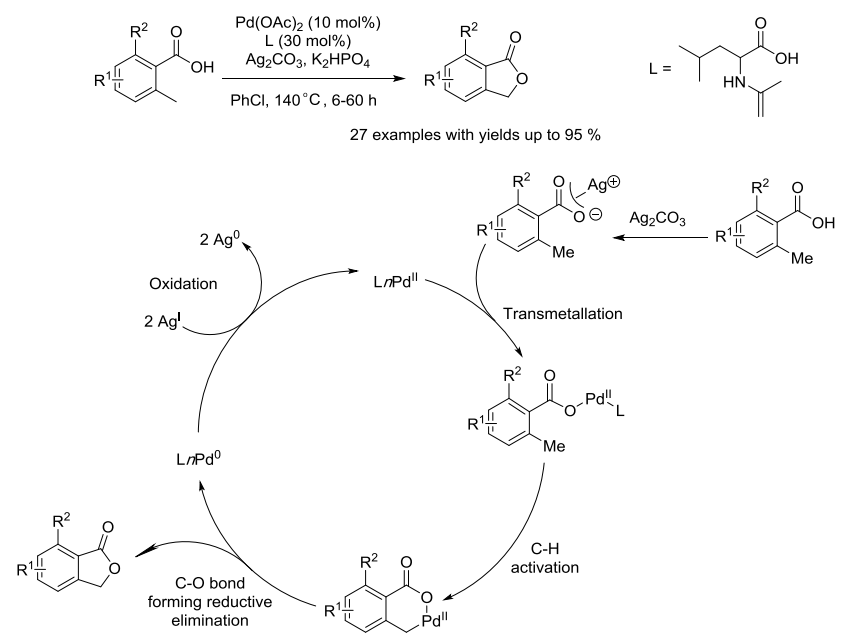

Using the $\mathrm{Pd}(\mathrm{OAc})_{2}$ and $\mathrm{Ag}_{2} \mathrm{O}$, Lee et al. ${ }^{[9]}$ established the coupling $\mathrm{C}-\mathrm{C}$ and $\mathrm{C}-\mathrm{O}$ reaction of ortho-benzoic acid to generate heterocyclic ring (Scheme 5). When the ortho-position of benzoic acid is hydrogen, the reaction yielded a six-member heterocyclic iscoumari. When the ortho-position of benzoic acid is $\mathrm{CH}_{3}$ or $\mathrm{OCH}_{3}$, the product is a five-member heterocyclic 3-substituted phthalide. According to the proposed mechanism, the coupling of styrene and benzoic acid undergoes a similar Heck coupling. When the ortho position of benzoic acid has steric hindrance, the migration and insertion of $\mathrm{Pd}$ tend to form a five-membered ring. Otherwise, it tends to form a six-membered ring. However, the system is only effective for electron-rich benzoic acid and styrene.

Scheme 5 Pd catalyzed coupling of benzoic acid with styrene and proposed mechanism

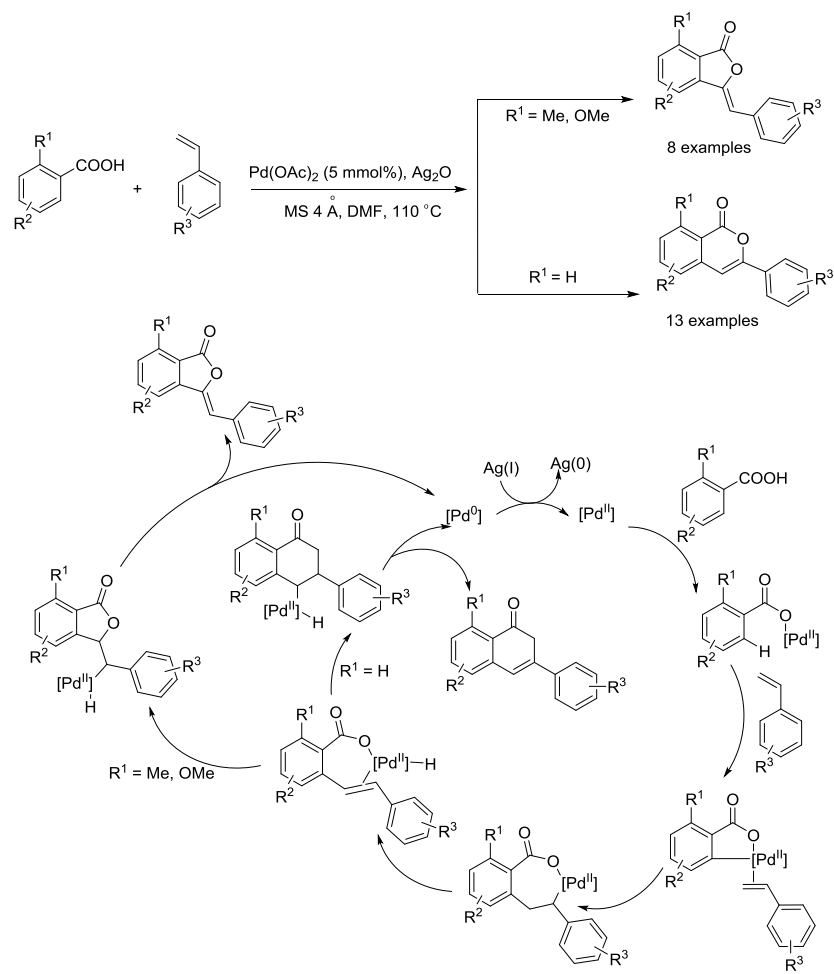

Lately, Zeng et al. ${ }^{[10]}$ developed a method for synthesis of phthalides using benzoic acid and bromoalkynes as substrates through carboxylate-directed ortho- $\mathrm{C}-\mathrm{H}$ activation. The reaction process was promoted by ligands with $\mathrm{Pd}(\mathrm{OAc})_{2}$ as catalyst (Scheme 6). The reaction has a wide range of substrates and a variety of phthalides have been synthesized by alkynylation-annulation.

Scheme 6 Cyclization of benzoic acid and bromoalkynes by ortho- $\mathrm{C}-\mathrm{H}$ activation

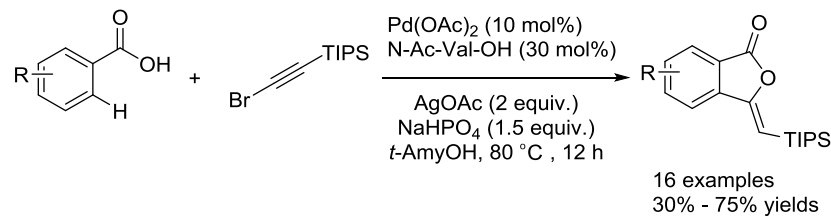

Almost in the same time, Gogoi et al. ${ }^{[11]}$ reported a novel decarbonylative alkyne insertion reaction to synthesize sixmembered compounds with $\mathrm{Pd}(\mathrm{II})$ as the catalyst (Scheme 7). According to the proposed mechanism, the cyclization reaction of hydroxynaphthoquinones and disubstituted alkynes was carried out through $\mathrm{C}-\mathrm{H} / \mathrm{C}-\mathrm{C}$ activation, acetylene insertion, 
Scheme 7 The decarbonylative alkyne insertion reaction cyclization reaction of hydroxynaphthoquinones and disubstituted alkynes and proposed mechanism
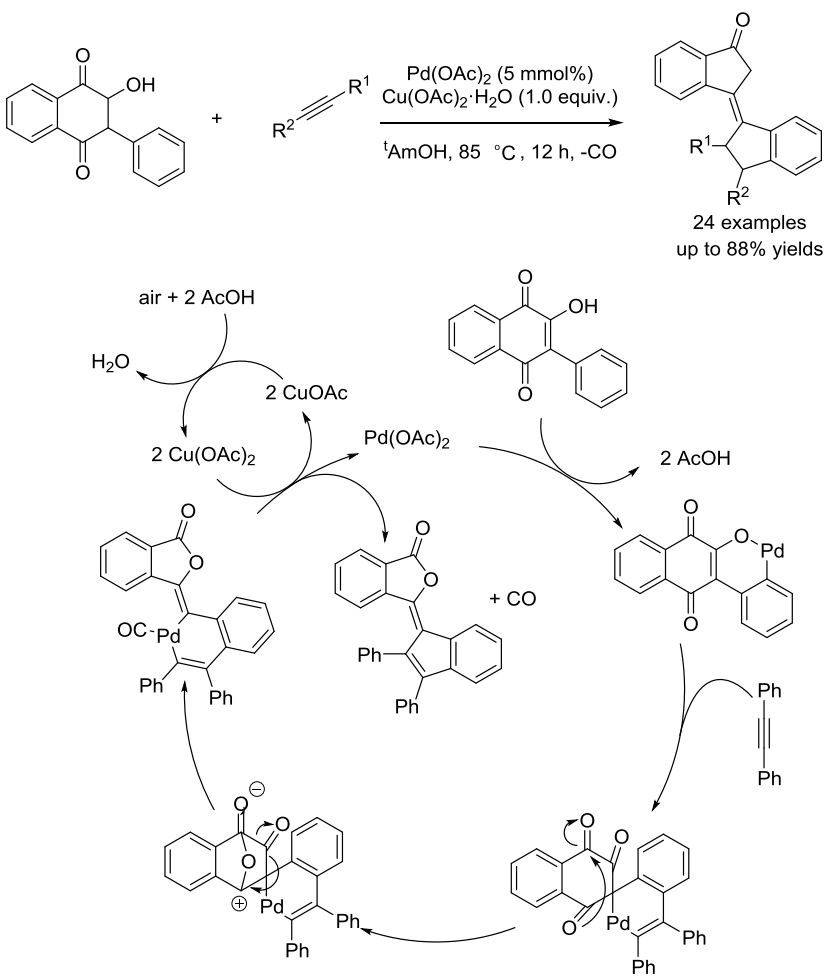

internal molecular cyclization and decarbonylation to obtain high yield 3-alkyl-phthalides.

\section{Synthesis of 3-Substituted Phthalides Using Rhodium Catalysts}

Rhodium catalysts are another type of transition metal catalysts in $\mathrm{C}-\mathrm{H}$ activation reactions, which is widely used in synthesis of 3-substituted phthalides.

In the presence of two silver additives ( $\mathrm{AgOTf}$ and $\mathrm{Ag}_{2} \mathrm{CO}_{3}$ ), $\left[\mathrm{Cp}^{*} \mathrm{RhCl}_{2}\right]_{2}$ can catalyze the reaction of benzoic acid ortho$\mathrm{C}-\mathrm{H}$ activation with aldehydes (Scheme 8$).{ }^{[12]}$ Both additives are necessary and neither of them is dispensable. The use of $\left[\mathrm{Cp}^{*} \mathrm{RhCl}_{2}\right]_{2}$ alone as a catalyst doesn't generate any desired product, which suggests that AgOTf is functioning as a chloride trapping agent to remove the chloride ligands from the $\left[\mathrm{Cp}^{*} \mathrm{RhCl}_{2}\right]_{2}$ complex and to generate the active species $\mathrm{Cp}^{*} \mathrm{Rh}{ }^{\text {III }}(\mathrm{OTf})_{2}$. With the help of $\mathrm{Ag}_{2} \mathrm{CO}_{3}$, benzoic acid is deprotonated, which coordinates to $\mathrm{Rh}$ (III) through one of the carboxylic oxygens. Since the Grignard type reaction occurs between a stable carbon anion and an electrophile, the highest yield can be obtained by coupling electron-rich acids with electron-deficient aldehydes.

The next reaction is similar to the above report and is carried out under similar conditions with $\left[\mathrm{Cp}^{*} \mathrm{RhCl}_{2}\right]_{2}$ catalyst and stoichiometric $\mathrm{Ag}_{2} \mathrm{CO}_{3}$ (Scheme 9). ${ }^{[13]}$ The difference in this reaction is that it's a dehydrogenation process, so $\mathrm{Ag}_{2} \mathrm{CO}_{3}$ acts as an oxidant here.

A strategy similar to the above approach involves replacing benzoic acid with $N$-substituted benzimidates (Scheme 10). ${ }^{[14]}$ The imidate group acts in the same way as the carboxyl group to promote ortho- $\mathrm{C}-\mathrm{H}$ activation, firstly by the insertion of aldehydes and then by the nucleophilic acyl substitution of the resulting alkoxide to the imidate. The final hydrolysis of the imidate affords phthalides.
Scheme 8 Rh-catalyzed annulative coupling of benzoic acid and aromatic aldehydes for the synthesis of 3-aryl phthalides and proposed mechanism

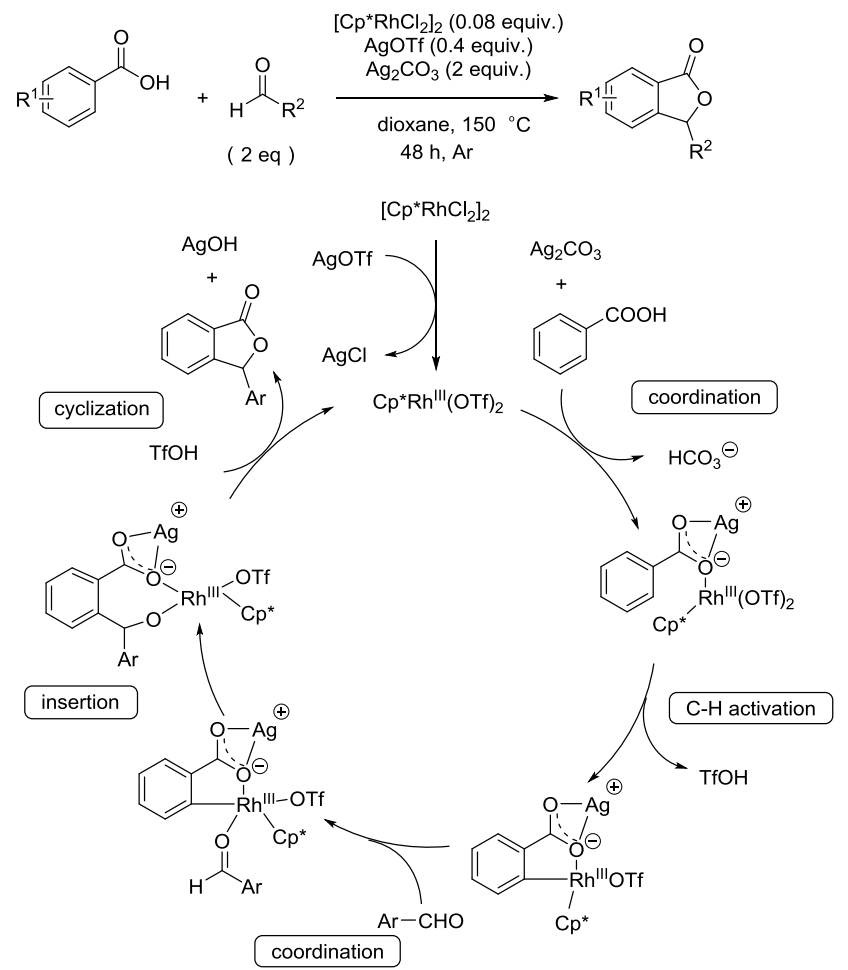

Scheme 9 Rh-catalyzed annulative coupling of benzaldehydes for the synthesis of 3-substituted phthalides

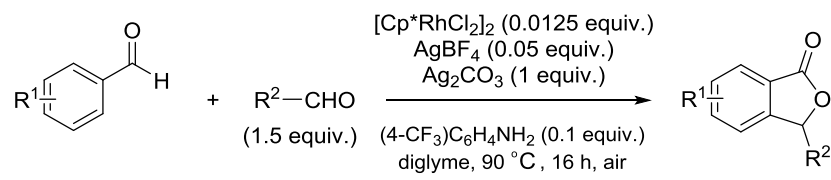

Scheme 10 Rh-catalyzed annulative coupling of methyl $\mathrm{N}$-substituted benzymidates and aldehydes for the synthesis of 3-substituted phthalides and proposed mechanism
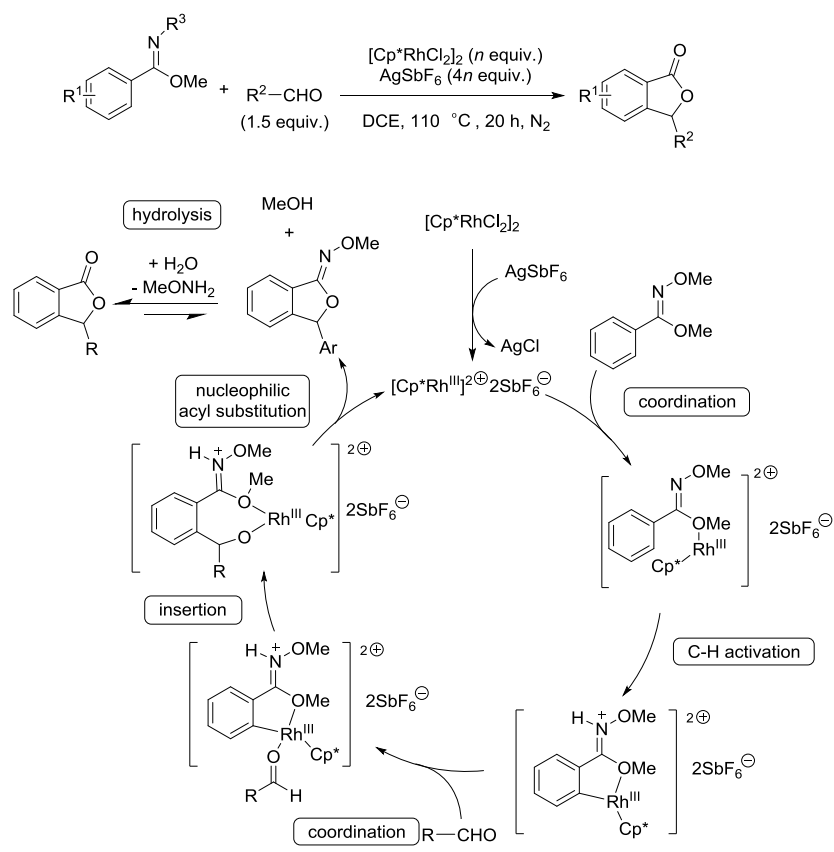


\section{Review}

Another method for synthesis of 3-substituted phthalides is chemoselective coupling of benzoic acid and alkenes, which uses $\left[\mathrm{Cp}^{*} \mathrm{RhCl}_{2}\right]_{2}$ as the catalyst and $\mathrm{NaClO}_{2}$ as the oxidant in $\mathrm{H}_{2} \mathrm{O} / \mathrm{AcOH}$ (Scheme 11). ${ }^{[15]}$ Because the yield is halved when acetic acid is substituted for pivalic acid or trifluoroacetic acid, the nature of the additive acid is crucial to the outcome of the reaction.

Scheme 11 Rh-catalyzed annulative coupling of benzoic acids and electrophilic alkenes for synthesis of 3-substituted phthalides in the presence of $\mathrm{Cl}(\mathrm{III})$ and proposed mechanism
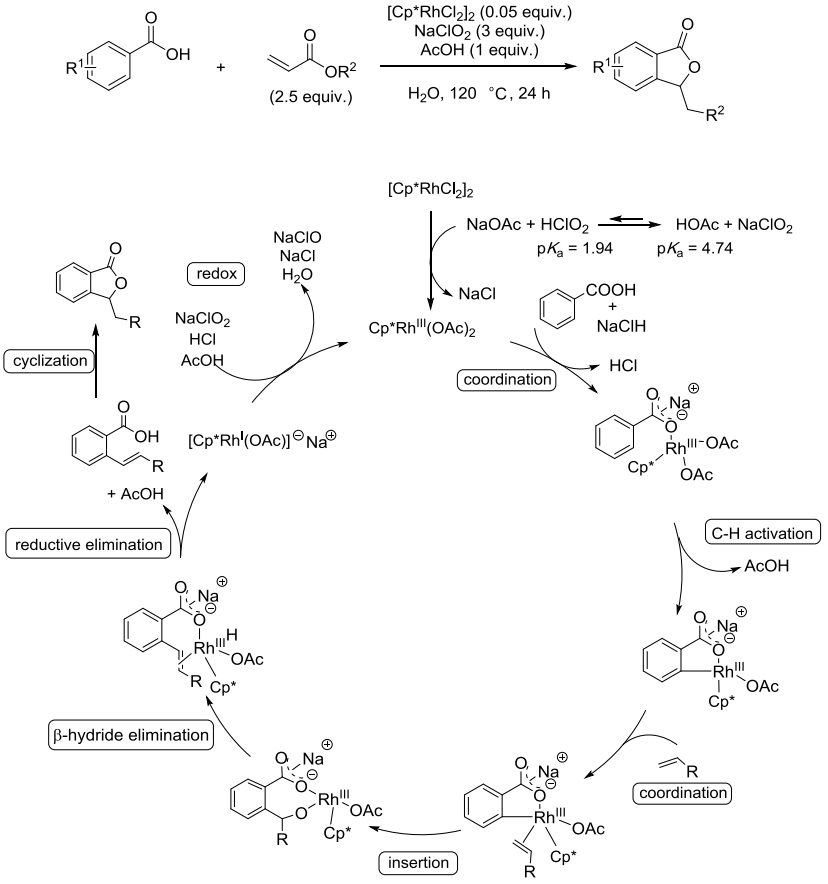

An additional method for synthesis of 3-substituted phthalides uses benzoic acids and alkenes as substrates, $[(\mathrm{COD}) \mathrm{RhCl}]_{2}$ as a catalyst, $\mathrm{Cu}(\mathrm{OAc})_{2} \cdot \mathrm{H}_{2} \mathrm{O}$ as an oxidant, and dicyclopentadiene (DCPD) as an additive (Scheme 12). ${ }^{[16]}$ Under such conditions, chemoselectivity depends on alkene type: $\alpha, \beta$-unsaturated ketones and amides afford 3-substituted phthalides exclusively ( 1 and 2 ); $\alpha, \beta$-unsaturated esters and aromatic vinyl sulfones provide a mixture of 3 -substituted and 3,7-disubstituted products $(\mathbf{4} \mathbf{a}+\mathbf{4} \mathbf{b}$ and $\mathbf{5 a}+\mathbf{5 b})$; ethyl vinyl sulfone only affords a 3,7-disubstituted product (3).

Similar to the above reactions, Jiang et al. ${ }^{[17]}$ reported that $\mathrm{Rh}$ (III) can catalyze the coupling reaction of benzoic acid and olefins in the oxygen environment (Scheme 13). The difference is that this reaction produced a mixture of mono- and di-substituted products. The primary product depends on the nature and location of substituents on the benzene ring: $m$-substituted benzoic acids mainly afford 3-substituted phthalides (9a); unsubstituted and $p$-substituted benzoic acids preferentially give 3,7-disubstituted phthalides ( $6 \mathbf{b}$ and $\mathbf{7 b}$ ).

When $\left[\mathrm{Cp}^{*} \mathrm{RhCl}_{2}\right]_{2}$ is used as a catalyst in the presence of $\mathrm{Cu}(\mathrm{OAc})_{2} \cdot \mathrm{H}_{2} \mathrm{O}$ and $\mathrm{o}$-xylene as solvent, the reaction of alkyl acrylates and benzoic acid does not provide monosubstituted products. ${ }^{[18]}$ Instead, two disubstituted products were obtained: 3-alkyl-7-vinylphthalide (10a or 11a) and 3-alkylidene-7vinylphthalide (10b or 11b) (Scheme 14). The result is different from the reaction seen before.

Benzamide may be used instead of benzoic acid as the substrate for synthesis of phthalide, ${ }^{[19]}$ but only a tertiary benzamide can be used. The best results are obtained from benzimidazole benzoamide derivatives as reported (Scheme 15).
Scheme 12 Rh-catalyzed annulative coupling of benzoic acids and electrophilic alkenes for synthesis of 3-substituted phthalides in the presence of $\mathrm{Cu}$ (II)

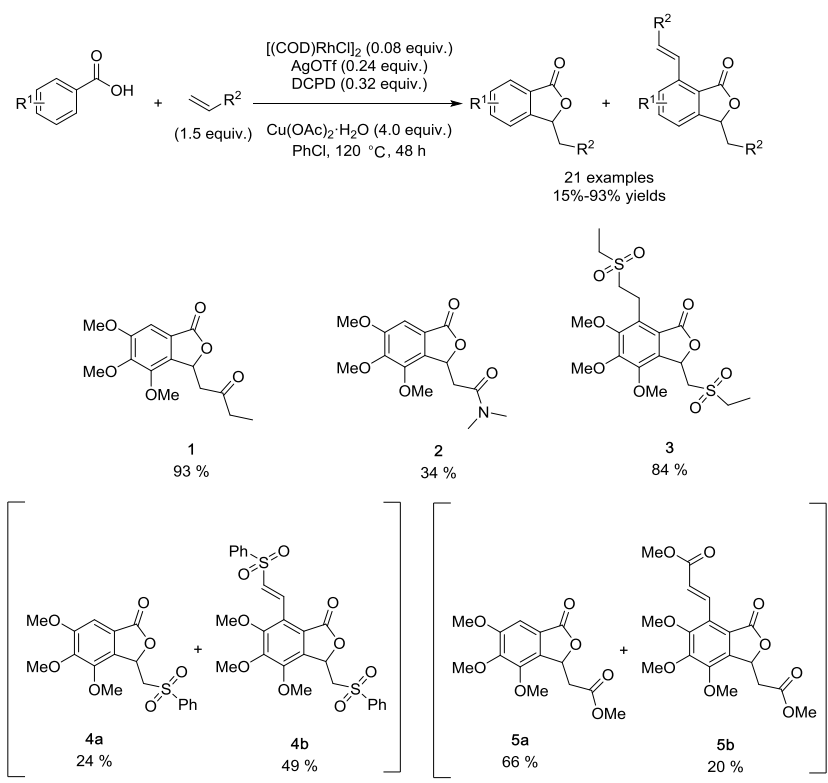

Scheme 13 Rh-catalyzed annulative coupling of benzoic acids and electrophilic alkenes for synthesis of 3-substituted phthalides in the presence of $\mathrm{O}_{2}$

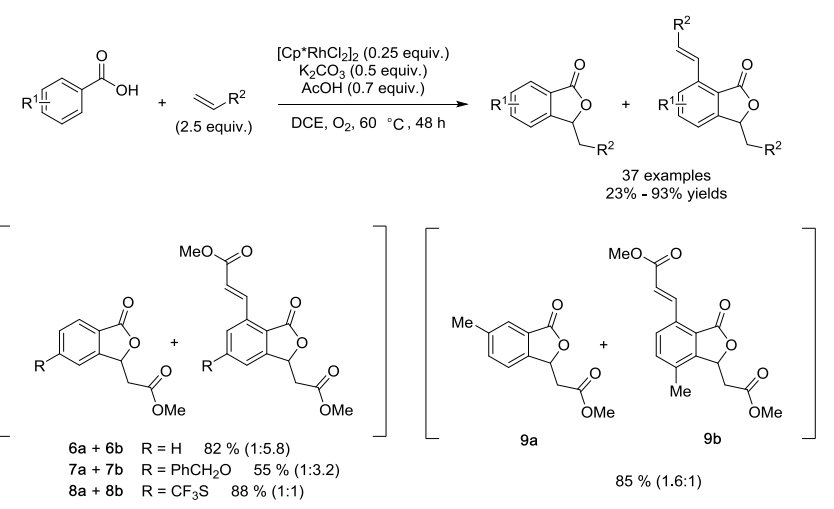

Scheme 14 Rh-catalyzed annulative coupling of benzoic acid and electrophilic alkenes for synthesis of 3-alkyl- and 3-ylidene phthalides

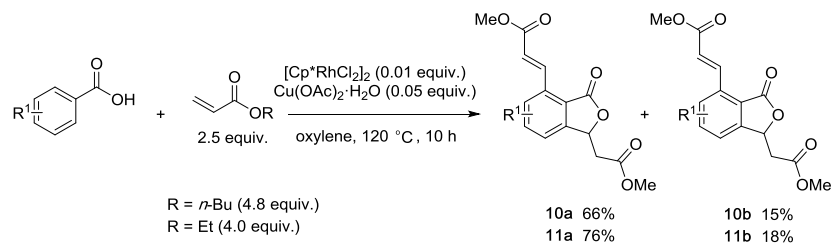

Acid additive $(\mathrm{AcOH})$ and low-polarity solvent (DCE) must be used to achieve maximum yield and better chemical selectivity. The annulative coupling likely consists of four tandem reactions: (1) an olefination, in which benzimidazole acts as a directing group; (2) an acetylation, in which benzimidazole acts as a leaving group and is replaced by acetate; (3) acetate hydrolysis with liberation of the $\mathrm{COOH}$ group; and (4) cyclization.

The method of enantioselective synthesis of 3-substituted phthalides is ketone hydroacylation with the ee values up to $97 \%$, and the key to the reaction is the cationic diphosphine $\mathrm{Rh}(\mathrm{I})$ complex. ${ }^{[20]}$ When toluene was heated in the presence of 
Scheme 15 Rh-catalyzed annulative coupling of $\mathrm{N}$-benzoyl benzimidazole and electrophilic alkenes for synthesis of 3-substituted phthalides and proposed mechanism

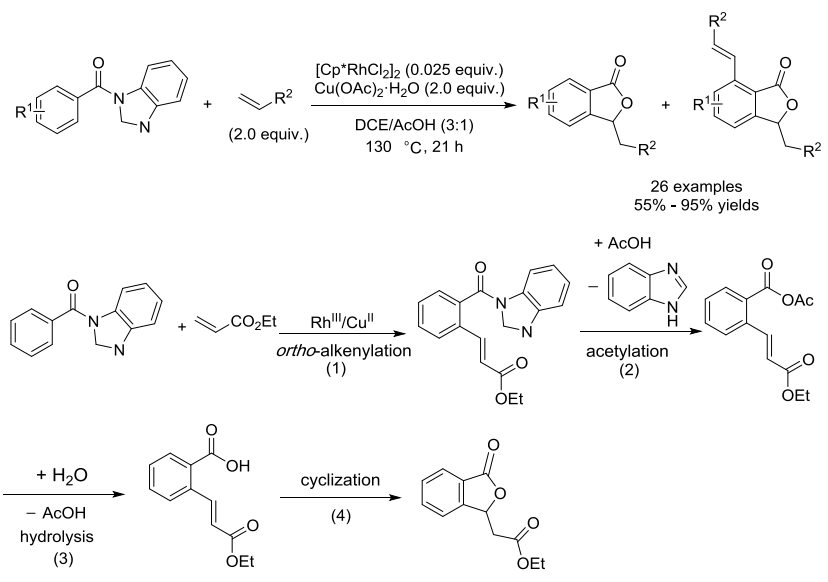

Scheme 16 Rh-catalyzed hydroacylation of o-ketobenzaldehydes for the synthesis of 3-substituted phthalides<smiles>[R]C(=O)c1c[R1]ccc1C(=O)O</smiles>

$\left[(\mathrm{COD}) \mathrm{RhCl}_{2}(0.05-0.15\right.$ equiv. $)$ $\mathrm{AgNO}_{3}(0.05-0.10$ equiv.) duanphos ( $0.05-0.10$ equiv.) $\mathrm{PhCH}_{3}, 75-100{ }^{\circ} \mathrm{C}, 1-3.5 \mathrm{~d}$<smiles>[R]C1OC(=O)c2c[R1](F)ccc21</smiles>
16 examples $67 \%-97 \%$ yields $13 \%-97 \%$ ee

$[\mathrm{Rh}(\mathrm{COD}) \mathrm{Cl}]_{2}$, duanphos and $\mathrm{AgNO}_{3}$ (Scheme 16), 2-acylbenzaldehydes was cycled into 3-substituted phthalides. It is the chiral active species [Rh(Duanphos) $]^{+} \mathrm{NO}_{3}{ }^{-}$that causes enantioselectivity.

\section{Synthesis of 3-Substituted Phthalides Using Ruthenium Catalysts}

Ruthenium catalysts are one of type transitionmetal catalysts widely used in $\mathrm{C}-\mathrm{H}$ activation reactions to obtain 3-substituted phthalides.

Benzoic acid and electrophilic olefins as substrates, but only acrylonitriles and acrylic esters as alkenes, a completely chemoselective method for synthesis of 3-alkyl phthalides is established using $\left[\mathrm{RuCl}_{2}(\mathrm{p} \text {-cymene })\right]_{2}$ as a catalyst and $\mathrm{Cu}(\mathrm{OAc})_{2} \cdot \mathrm{H}_{2} \mathrm{O}$ as an oxidant in water (Scheme 17). ${ }^{[1]}$ The scheme is suitable for substrates with electron-withdrawing and electron-donating groups attached to the benzene ring.

Scheme 17 Ru-catalyzed coupling of benzoic acids and electrophilic alkenes in water for synthesis of 3-substituted phthalides

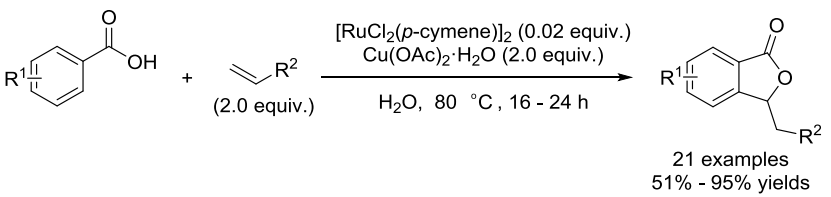

In 2015, Cai et al. ${ }^{[22]}$ reported the similar reaction conditions as above. If water was replaced with a mixture of polyethylene glycol 400 (PEG-400) and water $(3: 2, w / w)$, the catalyst in the coupling of benzoic acid and electrophilic alkenes could be recycled for 6 times without losing the catalytic activity (Scheme 18). This may be due to the coordination between polymer oxygen and metal, and PEG- $400 / \mathrm{H}_{2} \mathrm{O}$ mixture has strong adsorption capacity for both metal complexes.
Scheme 18 Ru-catalyzed annulative coupling of benzoic acids and electrophilic alkenes in PEG-400/water for synthesis of 3-substituted phthalides and proposed mechanism

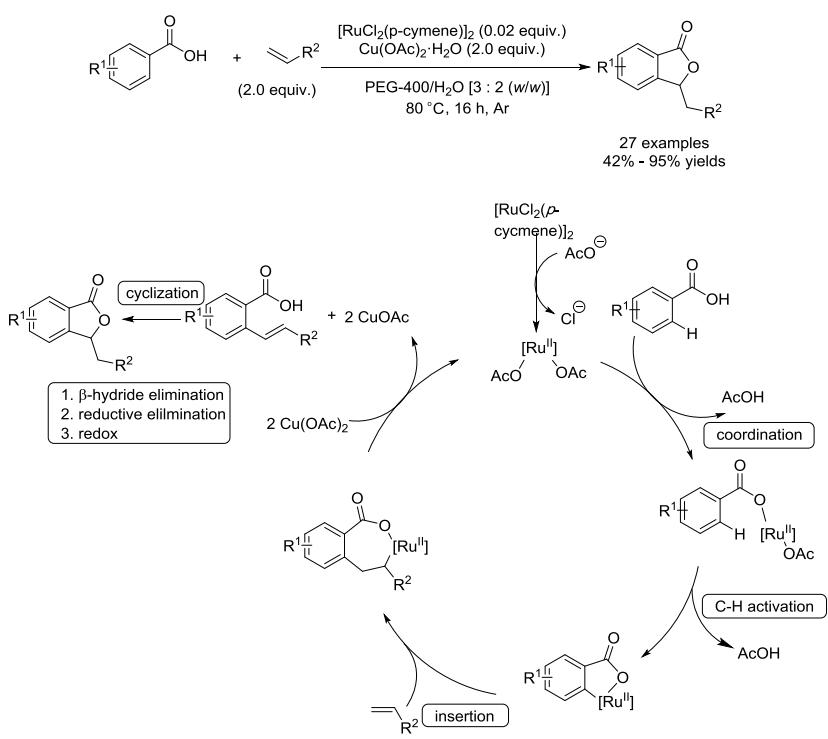

In a similar manner, Baidya and co-workers developed ${ }^{[23]}$ $\mathrm{Ru}(\mathrm{II})$-catalyzed annulative coupling from benzoic acids and aryl vinyl sulfones with acetonitrile as the solvent (Scheme 19).

Scheme 19 Ru-catalyzed annulative coupling of benzoic acids and electrophilic alkenes for the synthesis of 3-substituted phthalides

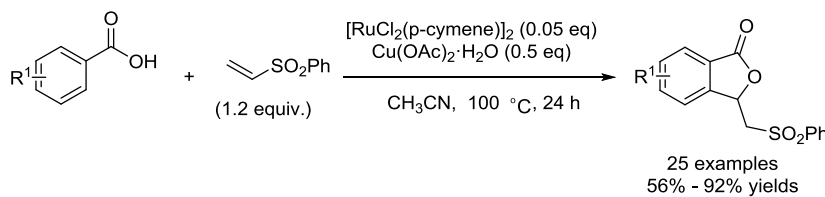

Another method of ruthenium-catalyzed cyclization of benzoic acid and olefin uses $\mathrm{O}_{2}$ as an oxidant (Schemes 20). ${ }^{[24,25]}$ Since the only by-product in the reaction is water, this method is more environmentally friendly than other methods involving metal oxidants.

Scheme 20 Ru-catalyzed annulative coupling of benzoic acids and electrophilic alkenes for synthesis of 3-substituted phthalides in GVL in the presence of $\mathrm{O}_{2}$

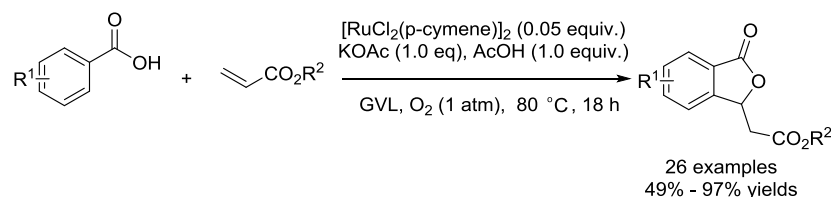

Ruthenium hydrides reported by Omura et al. ${ }^{[26]}$ could convert dialdehydes into lactones. ${ }^{[27-29]}$ With phthalaldehyde as a substrate and $\mathrm{RuHCl}(\mathrm{CO})\left(\mathrm{PPh}_{3}\right)_{3}$ as a catalyst, phthalaldehyde could successfully convert into phthalide after heating in toluene (Scheme 21). The reaction involves an intramolecular Tishchenko-type lactonization, which consists of three steps: (1) hydroruthenation of the keto carbonyl group with formation of an alkoxyruthenium complex, (2) intramolecular alkoxy-ruthenation of aldehyde carbonyl to provide acetal-type complex, and (3) $\beta$-hydride elimination to liberate phthalide. 


\section{Review}

Scheme 21 Ru-catalyzed hydroacylation of o-ketobenzaldehydes for synthesis of 3-substituted phthalides and proposed mechanism

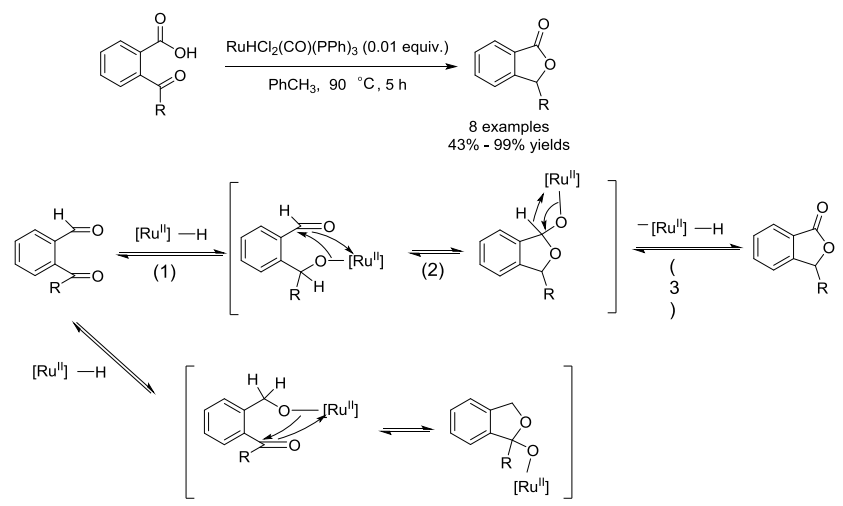

Scheme 22 Co-catalyzed hydroacylation of o-ketobenzaldehydes to afford 3-substituted phthalides<smiles></smiles>

$$
\begin{gathered}
\mathrm{CoBr}_{2} \text { (0.1 equiv.) } \\
\ln (0.2 \text { equiv.) } \\
\mathrm{R}, \mathrm{R}-\mathrm{Ph}-\mathrm{BPE}(0.1 \text { equiv. }) \\
\hline \mathrm{MeCN}, 80^{\circ} \mathrm{C}, 12 \mathrm{~h}
\end{gathered}
$$<smiles>[R]C1OC(=O)c2ccncc21</smiles>

17 examples $53 \%-97 \%$ yields $82 \%-98 \%$ ee

\section{Synthesis of 3-Substituted Phthalides from Other Transition Metal Catalysts}

Yang et al. ${ }^{[30]}$ developed a method to prepare 3-substituted phthalides with high enantioselectivity. In the presence of indium metal, $\mathrm{CoBr}_{2}$ was reduced in situ to produce chiral $\mathrm{Co}(0)$ diphosphine complex (Scheme 22), and acetonitrile was used as solvent and the reaction temperature needs $80^{\circ} \mathrm{C}$.

In 2019, Wang et al. ${ }^{[31]}$ reported [4+1] cyclization catalyzed by metal rhenium $(R e)$ with benzamides and aldehydes as substrates, which provides a convenient method for synthesis of phthalide derivatives (Scheme 23). It shows a unique reaction pattern compared to the above catalysis using $\mathrm{Rh}$ and $\mathrm{Pd}$ in terms of the simplicity of the initial substrates, various electrical substrate types, and elimination of by-products. Notably, after this reaction has undergone coordination, $\mathrm{C}-\mathrm{H}$ bond activation, and insertion processes, quenching of $A$ with acid gives alcohol $\mathrm{B}$, which undergoes intramolecular $\mathrm{N}$ - or $\mathrm{O}$-attacked cyclization, affording lactam $\mathrm{C}$ or iminoether $\mathrm{D}$, respectively. The $\mathrm{O}$-attacked cyclization is preferred in the reactions of electrondeficient and electron-neutral aldehydes to afford iminoether $D$. Then, the acid-promoted hydrolysis of $D$ gives rise to the formation of the final product $\mathrm{E}$. When electron-rich aldehydes are used, the $\mathrm{N}$-attacked cyclization might occur to afford lactam $\mathrm{C}$ from alcohol $\mathrm{B}$.

Lately, Kuninobu et al. ${ }^{[32]}$ reported synthesis of phthalides from benzoate and propylene oxide via $\mathrm{C}-\mathrm{H}$ bond activation mediated by manganese and borone (Scheme 24). In their research, triphenylborone is essential to facilitate the reaction. This is an example of an oxygen guiding group assisting manganese to catalyze the $\mathrm{C}-\mathrm{H}$ activation.

Electrochemical $\mathrm{C}-\mathrm{H}$ activation with iridium catalysis was also studied by Ackermann and co-workers, ${ }^{[33]}$ which was synergistic by redox catalysts (Scheme 25). Iridium catalytic electrosynthesis has a wide range of substrate applications and good tolerance to various functional groups, especially to the
Scheme 23 Re-catalyzed cyclization of benzamides and aldehydes to afford 3-substituted phthalides and proposed mechanism

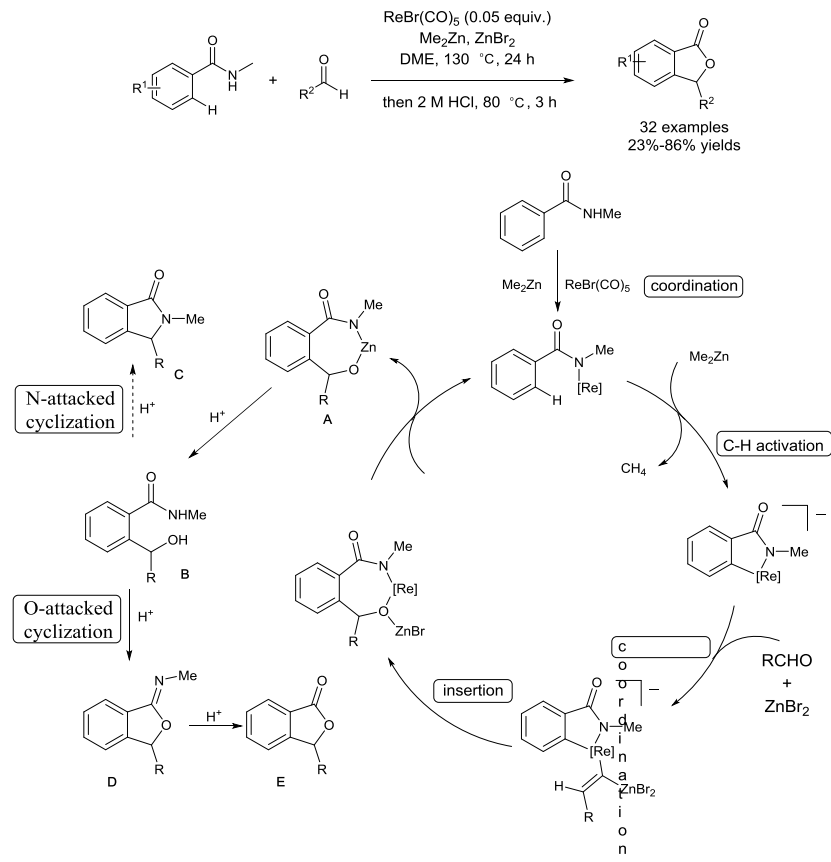

Scheme 24 Mn-catalyzed synthesis of 3-substituted phthalides and proposed mechanism
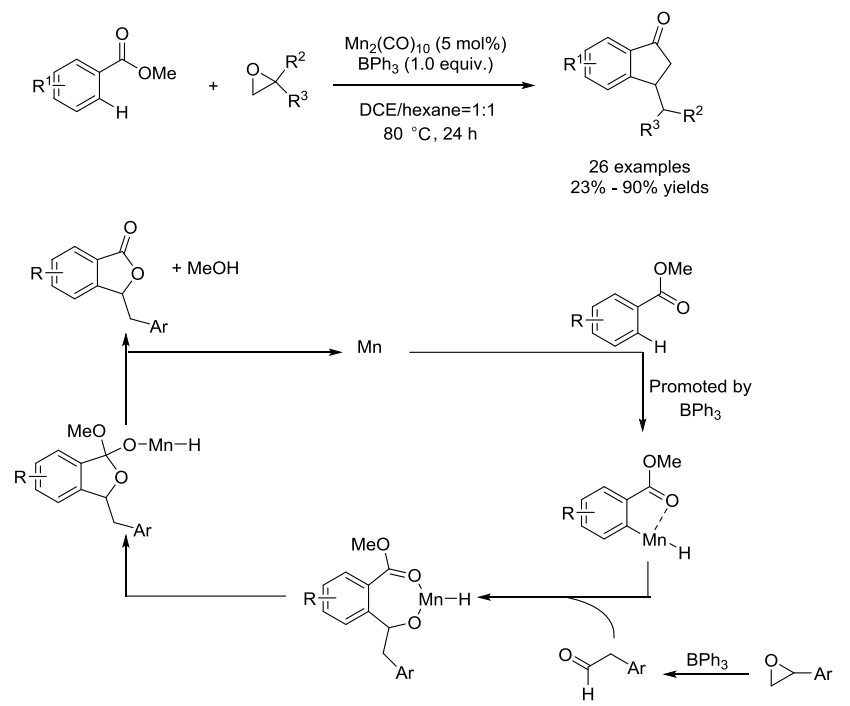

Scheme 25 Iridium-catalyzed $\mathrm{C}-\mathrm{H}$ activation by synergistic electrocatalysis

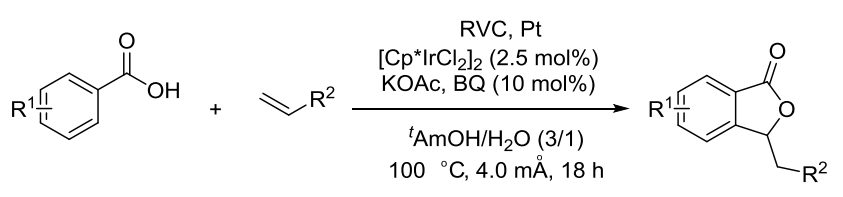

34 examples $50 \%-87 \%$ yields

chemical sensitive bromine and iodide aromatics.

\section{Conclusions and Perspectives}

So far, nearly 30 protocols through $\mathrm{C}-\mathrm{H}$ activation have been developed for direct synthesis of 3-substituted phthalides. Nowadays, it becomes more and more potent tool for synthesis 
of these phthalide derivatives. However, there are still two challenges in the following: (1) There is no direct or semi-direct method to construct the 3-substituted phthalide with a saturated alkyl chain at the 3-position; (2) The large number of factors (substrate, catalyst, oxidant, additives, solvent, as well as reagents ratio and concentration) that affect chemo- and regio-selectivity and are difficult to control. Thus, these aspects mentioned above still should be further improved to establish more effective strategies to synthesis of 3-substituted phthalides via $\mathrm{C}-\mathrm{H}$ activation, and the steric configuration of the 3-position substitution of phthalides is also effectively controlled through the selective use of chiral catalysts. In the meantime, besides transition metals used to catalyze the reaction, photochemical and electrochemical catalyzed reactions via the activation of $\mathrm{C}-\mathrm{H}$ bond to construct the 3-substituted phthalide are also vigorously developed now.

\section{Acknowledgement}

This work was supported by the program for the Science and Technology Innovation Talents in Universities of Henan Province (Grant No. 17HASTIT043) and the support project for the Disciplinary group of Psychology and Neuroscience, Xinxiang Medical University (Grant No. 2016PN-KFKT-15).

Copyright ( 2021 Qianqian Sun, Runqing Zhu, Shuyu Hu, and Lizhen Fang. This article is an open access article distributed under the terms and conditions of the Creative Commons Attribution (CC BY) license (http://creativecommons.org/licenses/by/4.0/). The use, distribution or reproduction in other forums is permitted, provided the original author(s) or licensor are credited and that the original publication in this journal is cited, in accordance with accepted academic practice. No use, distribution or reproduction is permitted which does not comply with these terms.

\section{References}

[1] Kohn, L. K.; Pavam, C. H.; Veronese, D.; Coelho, F.; De Carvalho, J. E.; Almeida, W. P. Antiproliferative effect of Baylis-Hillman adducts and a new phthalide derivative on human tumor cell lines. Eur. J. Med. Chem. 2006, 41, 738-744.

[2] Lin, G.; Chan, S. S. K.; Chung, H. S.; Li, S. L. Chemistry and biological activities of naturally occurring phthalides. Nat. Prod. Chem. 2005, 32, 611-669.

[3] Beck, J. J.; Chou, S. C. The structural diversity of phthalides from the Apiaceae. J. Nat. Prod. 2007, 70, 891-900.

[4] Wang, W.; Cha, X. X.; Reiner, J.; Gao, Y.; Qiao, H. L.; Shen, J. X.; Chang, J. B. Synthesis and biological activity of $n$-butylphthalide derivatives. Eur. J. Med. Chem. 2010, 45, 1941-1946.

[5] Qiang, X.; Li, Y.; Yang, X.; Luo, L.; Xu, R.; Zheng, Y.; Cao, Z.; Tan, $Z$.; Deng, Y. DL-3-n-butylphthalide-Edaravone hybrids as novel dual inhibitors of amyloid- $\beta$ aggregation and monoamine oxidases with high antioxidant potency for Alzheimer's therapy. Bioorg. Med. Chem. Lett. 2017, 27, 718-722.

[6] Miura, M.; Tsuda, T.; Satoh, T.; Pivsaart, S.; Nomura, M. Oxidative Cross-Coupling of $N$-(2'-Phenylphenyl)benzenesulfonamides or Benzoic and Naphthoic Acids with Alkenes Using a PalladiumCopper Catalyst System under Air. J. Org. Chem. 1998, 63, 5211-5215.

[7] Zhang, Y. H.; Shi, B. F.; Yu, J. Q. Palladium(II)-catalyzed orthoalkylation of benzoic acids with alkyl halides. Angew. Chem. Int. Ed. Engl. 2009, 48, 6097-6100.

[8] Novak, P.; Correa, A.; Gallardo-Donaire, J.; Martin, R. Synergistic palladium-catalyzed $\mathrm{C}\left(\mathrm{sp}^{3}\right)-\mathrm{H}$ activation/ $\mathrm{C}\left(\mathrm{sp}^{3}\right)-\mathrm{O}$ bond formation: a direct, step-economical route to benzolactones. Angew. Chem. Int. Ed. Engl. 2011, 50, 12236-12239.
[9] Nandi, D.; Ghosh, D.; Chen, S. J.; Kuo, B. C.; Wang, N. M.; Lee, H. $M$. One-step synthesis of isocoumarins and 3-benzylidenephthalides via ligandless Pd-catalyzed oxidative coupling of benzoic acids and vinylarenes. J. Org. Chem. 2013, 78, 3445-3451.

[10] Shi, S.; Chen, C. H.; Chai, Y.; Zhang, L. T.; Li, J. W.; Liu, B.; Liu, Y. J.; Zeng, M. H. Switchable Synthesis of Arylalkynes and Phthalides via Controllable Palladium-Catalyzed Alkynylation and Alkynylation-Annulation of Benzoic Acids with Bromoalkynes. J. Org. Chem. 2019, 84, 9161-9168.

[11] Borthakur, S.; Baruah, S.; Sarma, B.; Gogoi, S. Pd(II)-Catalyzed Synthesis of Alkylidene Phthalides via a Decarbonylative Annulation Reaction. Org. Lett. 2019, 21, 2768-2771.

[12] Shi, X. Y.; Li, C. J. A Novel Rhodium-Catalyzed Cascade Cyclization: Direct Synthesis of 3-Substituted Phthalides from Aldehydes and Aromatic Acids. Adv. Synth. Catal. 2012, 354, 2933-2938.

[13] Tan, P. W.; Juwaini, N. A. B.; Seayad, J. Rhodium (III)-Amine Dual Catalysis for the Oxidative Coupling of Aldehydes by Directed C-H Activation: Synthesis of Phthalides. Org. Lett. 2013, 15, 5166-5169.

[14] Lian, Y.; Bergman, R. G.; Ellman, J. A. Rhodium(III)-catalyzed synthesis of phthalides by cascade addition and cyclization of benzimidates with aldehydes. Chem. Sci. 2012, 3, 3088-3092.

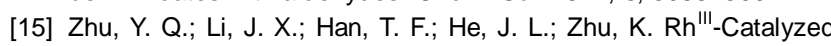
Regioselective Synthesis of Phthalides with Water as the Solvent. Eur. J. Org. Chem. 2017, 2017, 806-811.

[16] Renzetti, A.; Nakazawa, H.; Li, C. J. Rhodium-catalysed tandem dehydrogenative coupling-Michael addition: direct synthesis of phthalides from benzoic acids and alkenes. RSC Adv. 2016, 6 , 40626-40630.

[17] Jiang, Q.; Zhu, C.; Zhao, H.; Su, W. Rh'I'-Catalyzed C-H Olefination of Benzoic Acids under Mild Conditions using Oxygen as the Sole Oxidant. Chem. Asian. J. 2016, 11, 356-359.

[18] Ueura, K.; Satoh, T.; Miura, M. An Efficient Waste-Free Oxidative Coupling via Regioselective $\mathrm{C}-\mathrm{H}$ Bond Cleavage: $\mathrm{Rh} / \mathrm{Cu}$ Catalyzed Reaction of Benzoic Acids with Alkynes and Acrylates under Air. Org. Lett. 2007, 9, 1407-1409.

[19] Mishra, N. K.; Park, J.; Choi, M.; Sharma, S.; Jo, H.; Jeong, T.; Han, S.; Kim, S.; Kim, I. S. Synthesis of Phthalides through Tandem Rhodium-Catalyzed C-H Olefination and Annulation of Benzamides. Eur. J. Org. Chem. 2016, 2016, 3076-3083.

[20] Phan, D. H. T.; Kim, B.; Dong, V. M. Phthalides by RhodiumCatalyzed Ketone Hydroacylation. J. Am. Chem. Soc. 2009, 131, 15608-15609.

[21] Ackermann, L.; Pospech, J. Ruthenium-Catalyzed Oxidative C-H Bond Alkenylations in Water: Expedient Synthesis of Annulated Lactones. Org. Lett. 2011, 13, 4153-4155.

[22] Zhao, H.; Zhang, T. L.; Yan, T.; Cai, M. Z. Recyclable and Reusable $\left[\mathrm{RuCl}_{2}(\mathrm{p} \text {-cymene })\right]_{2} / \mathrm{Cu}(\mathrm{OAc})_{2} / \mathrm{PEG}-400 / \mathrm{H}_{2} \mathrm{O}$ System for Oxidative $\mathrm{C}-\mathrm{H}$ Bond Alkenylations: Green Synthesis of Phthalides. J. Org. Chem. 2015, 80, 8849-8855.

[23] Mandal, A.; Dana, S.; Chowdhury, D.; Baidya, M. Ru"-Catalyzed Annulative Coupling of Benzoic Acids with Vinyl Sulfone via Weak Carboxylate-Assisted C-H Bond Activation. Asian J. Org. Chem. 2018, 7, 1302-1306.

[24] Bechtoldt, A.; Tirler, C.; Raghuvanshi, K.; Warratz, S.; Kornhaass, C.; Ackermann, L. Ruthenium Oxidase Catalysis for Site-Selective C-H Alkenylations with Ambient $\mathrm{O}_{2}$ as the Sole Oxidant. Angew. Chem. Int. Ed. Engl. 2016, 128, 272-275.

[25] Bechtoldt, A.; Baumert, M. E.; Vaccaro, L.; Ackermann, L. Ruthenium(II) oxidase catalysis for $\mathrm{C}-\mathrm{H}$ alkenylations in biomassderived y-valerolactone. Green Chem. 2018, 20, 398-402.

[26] Omura, S.; Fukuyama, T.; Murakami, Y.; Okamoto, H.; Ryu, I. Hydroruthenation triggered catalytic conversion of dialdehydes and keto aldehydes to lactones. Chem. Commun. (Camb). 2009, 6741-6743.

[27] Hiroshi, H.; Takashi, I.; Akio, Y. A New Tishchenko-Type Ester 
Formation Catalyzed by Rythenium Complexes. Chem. Lett. 1978, 7, 17-20.

[28] Takashi, I.; Hiroshi, H.; Yoshitaka, K.; Akio, Y. Selective Dimerization of Aldehydes to Esters Catalyzed by Hydridoruthenium Complexes. Bull. Chem. Soc. Jpn. 1982, 55, 504-512.

[29] Murahashi, S.; Naota, T.; Ito, K.; Maeda, Y.; Taki, H. RutheniumCatalyzed Oxidative Transformation of Alcohols and Aldehydes to Esters and Lactones. J. Org. Chem. 1987, 52, 4319-4327.

[30] Yang, J.; Yoshikai, N. Cobalt-catalyzed enantioselective intramolecular hydroacylation of ketones and olefins. J. Am. Chem. Soc. 2014, 136, 16748-16751.

[31] Jia, B.; Yang, Y.; Jin, X.; Mao, G.; Wang, C. Rhenium-Catalyzed Phthalide Synthesis from Benzamides and Aldehydes via $\mathrm{C}-\mathrm{H}$
Bond Activation. Org. Lett. 2019, 21, 6259-6263.

[32] Sueki, S.; Wang, Z.; Kuninobu, Y. Manganese- and BoraneMediated Synthesis of Isobenzofuranones from Aromatic Esters and Oxiranes via C-H Bond Activation. Org. Lett. 2016, 18, 304-307.

[33] Qiu, Y.; Stangier, M.; Meyer, T. H.; Oliveira, J. C. A.; Ackermann, L. Iridium-Catalyzed Electrooxidative $\mathrm{C}-\mathrm{H}$ Activation by Chemoselective Redox-Catalyst Cooperation. Angew. Chem. Int. Ed. Engl. 2018, 57, 14179-14183.

Received June 24, 2020

Accepted July 25, 2020 